\title{
Anatomical Study of Variations in the Branches of Superior Mesenteric Artery - A Study from a Teaching Hospital in Chennai, India
}

\author{
Ganga Venkatachalam ${ }^{1}$, Kanagavalli Paramasivam², Lakshmi Valliyappan ${ }^{3}$ \\ ${ }^{1}$ Department of Anatomy, Thoothukudi Medical College, Thoothukudi, Tamilnadu, \\ India. ${ }^{2}$ Department of Anatomy, Madras Medical College, Chennai, Tamilnadu, India. \\ ${ }^{3}$ Department of Anatomy, Stanly Medical College, Chennai, Tamilnadu, India.
}

\section{ABSTRACT}

\section{BACKGROUND}

Superior Mesenteric Artery (SMA) is one of the anterior branches of the abdominal aorta. It originates from abdominal aorta at the level of lower border of first lumbar vertebra, one centimeter below the coeliac trunk. It gives the first branch inferior pancreaticoduodenal artery (IPDA), The colic branches arise from concave right side of the superior mesenteric artery, these are middle colic artery (MCA), right colic artery (RCA), ileo colic artery (ICA). Jejunal and ileal branches arise from left side of the SMA. Superior mesenteric artery supplies derivatives of midgut. Knowledge of branching pattern of the SMA is clinically important to gastroenterologists operating on gut and neighboring structures like pancreas, duodenum, and liver. We wanted to study the variations in the branches of superior mesenteric artery.

\section{METHODS}

This is a descriptive study conducted on 50 adult embalmed human cadavers by conventional dissection method, the findings were noted and tabulated.

\section{RESULTS}

Present study shows that inferior pancreatic duodenal artery orginated from SMA in 47 (94\%) specimens. IPDA was absent in 3 (6\%) specimens. Middle colic artery was found to arise from SMA in $48(94 \%)$ and MCA was absent in 2 (4\%) specimens. Right colic artery was found to arise from SMA in 47 (94\%) specimens and it was absent in 3 (6\%) specimens. Ileo-colic artery was found to arise from SMA in all 50 (100\%) specimens.

\section{CONCLUSIONS}

Awareness of these complex variations may prevent devastating complications during colonic surgeries. Variations in the branching pattern of superior mesenteric artery is essential for surgeons operating on derivatives of midgut, liver, pancreas.
Corresponding Author: Dr. Kanagavalli Paramasivam, Associate Professor, Institute of Anatomy, Madras Medical College, Chennai, Tamilnadu, India. E-mail: drkanagashankar@gmail.com

DOI: $10.14260 /$ jemds/2021/315

How to Cite This Article: Venkatachalam G, Paramasivam K, Valliyappan L. Anatomical study of variations in the branches of superior mesenteric artery - a study from a teaching hospital in Chennai, India. J Evolution Med Dent Sci 2021;10(20):1506-1510, DOI: $10.14260 /$ jemds/2021/315

Submission 12-12-2020,

Peer Review 19-02-2021,

Acceptance 25-02-2021,

Published 17-05-2021.

Copyright (C) 2021 Ganga Venkatachalam et al. This is an open access article distributed under Creative Commons Attribution License [Attribution 4.0 International (CC BY 4.0)]

\section{KEY WORDS}

Branches, Colic, Superior Mesenteric Artery, Variations 


\section{BACKGROUND}

The Superior mesenteric artery (SMA) is the important artery of abdomen and supplies the organs of midgut which extends from the duodenum distal to the opening of the ampulla of vater, jejunum, ileum, caecum, appendix, ascending colon and the right two - third of the transverse colon.

The SMA originates from the ventral surface of the abdominal aorta one centimeter below the coeliac artery at the level of the lower border of first lumbar vertebra. ${ }^{1}$ From its origin, it runs anterior to the uncinate process of pancreas and the third part of the duodenum. It then slopes obliquely in the root of the mesentery to the right iliac fossa. It is accompanied by the superior mesenteric vein on its right.

The branches of the superior mesenteric artery are inferior pancreatic duodenal artery, middle colic artery, right colic artery , ileocolic artery, jejunal and ileal branches.

IPDA is the first branch of SMA. It divides into anterior and posterior branches which anastomose with corresponding branches of superior pancreatic duodenal artery (branch from coeliac artery). This anastomosis supplies the head of pancreas, uncinate process and duodenum.

- MCA arise from right side of the SMA and supplies transverse colon.

- RCA arise from right side of the SMA and supplies ascending colon.

- ICA is the last main branch of the SMA. It descends inferiorly and to the right, supplies the ascending colon, appendix, cecum and ileum.

Jejunal and ileal branches run between the two layers of the mesentery and form anastomotic arcades from which smaller straight branches (vasa recta) arise to supply the jejunum and ileum.

The recent development in the field of abdominal surgery such as pancreatic duodenal resection for carcinoma of the head of pancreas, oesophagojejunostomies, intestine transfers, resection of small and large intestines give a clearer appreciation and knowledge of the varied blood supply of the supra and infra colic organs. The integrity of the vascular structure in the vicinity of the SMA is of primary importance in the successful transplantation of liver and pancreas. So the knowledge of extremely variable blood supply to the abdominal organs by the superior mesenteric artery is very important to the surgeon, radiologist and the anatomist. 2,3,4,5,6,7,1,8

We wanted to study the variations in the branches of superior mesenteric artery. The current study is focused at the following parameters

A. Presence/Absence of inferior pancreatic duodenal artery

B. Anomalous origin of inferior pancreatic duodenal artery

C. Presence/Absence of middle colic artery (MCA)

D. Presence/Absence of right colic artery (RCA)

E. Presence/Absence of ileocolic artery (ICA)

F. Number of jejunal \& ileal branches

\section{METHODS}

The descriptive study of randomly selected fifty (50) adult embalmed human cadavers from the cadavers allotted to the first MBBS students and first BDS students at the Institute of
Anatomy, Madras Medical College, and Chennai - 3. Ethics committee approval obtained from Institutional ethics committee of Madras Medical College on 27-09-2011, No. 14092011. This study was conducted from Jan 2011 to April 2012 in Madras Medical College.

A midline skin incision was made and skin, superficial fascia and anterior abdominal wall muscles were reflected. The liver was pulled superiorly and the coeliac trunk was identified. The mesentery of the small intestine was exposed by turning the transverse colon and its mesentery upwards. The small intestine was turned to the left and the right layer of the mesentery was cut along the line of its attachment to the posterior abdominal wall, and striped it from its attachment. Branches of the superior mesenteric artery were traced. This is a descriptive study.

\section{Statistical Analysis}

The percentage of presence/absence of branches of The superior mesenteric artery (SMA) were noted and tabulated.

\section{RESULTS}

\section{Inferior Pancreatic Duodenal Artery}

In the present study the IPDA was observed in 47 (94\%) specimens. It was found to arise from the superior mesenteric artery in 39 (78 \%) specimens, from the first jejunal in $5(10$ $\%)$ specimens, from middle colic artery in 2 (4\%) specimens, and from second jejunal in 1 (2\%) specimen. IPDA was absent in $3(6 \%)$ specimens.

\begin{tabular}{|ccc|}
\hline IPD & No. of Specimens & Percentage \\
SMA & 39 & $78 \%$ \\
First jejunal & 5 & $10 \%$ \\
MCA & 2 & $4 \%$ \\
Second jejunal & 1 & $2 \%$ \\
Absent & 3 & $6 \%$ \\
\hline Table 1. Source of Origin of the Inferior Pancreaticoduodenal Artery \\
\hline
\end{tabular}

\section{Anomalous Origin of the IPDA}

In this study the IPDA was found to be absent in three (6\%) specimens out of fifty specimens dissected. In that case, it was compensated by the dorsal pancreatic branch, which came from the coeliac trunk.

\section{Middle Colic Artery}

In the present study, out of fifty specimens dissected, the MCA was found to arise from the superior mesenteric artery in 48 (96\%) specimens, and in 2 specimens (4\%) the MCA was found to be absent.

\section{Right Colic Artery}

In the present study out of fifty specimens dissected, RCA was found to be absent in three (6\%) specimens, and it was present in 47 (94\%) specimens. In those specimens in which the RCA was absent, it was compensated by the anastomosis between superior branch of ileo colic artery and the inferior branch of MCA. 


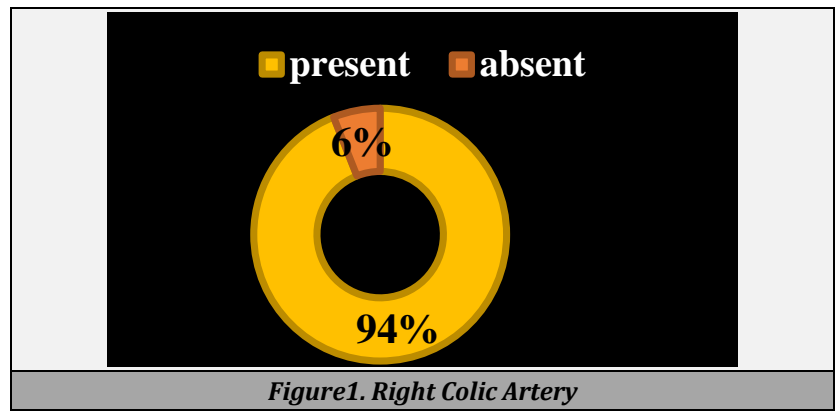

Ileo Colic Artery

In the current study, the ileo colic artery was observed in all fifty specimens.

\section{Jejunal and Ileal Branches}

In the present study the number of jejunal and ileal branches ranged from six to twelve. In ten $(20 \%)$ specimens the number of branches were six, in five (10\%) specimens there were seven branches, in eighteen (36\%) specimens there were eight branches, in six (12\%) specimens there were nine branches, in four (8\%) specimens three were ten branches and in seven $(14 \%)$ specimens there were twelve branches. The prevalent number of branches was eight branches in eighteen specimens.

\section{DISCUSSION}

Origin of Inferior Pancreaticoduodenal Artery In the present study, the IPDA arose from the SMA in 39 (78 $\%)$ specimens which coincides with Textbook on anatomy by Basmagian. V. John (1937), Hamilton. W.J (1956) who said that the IPDA arises from the SMA as the first branch.

In the present study, IPDA arose from first jejunal branch in $5(10 \% v)$ specimens which coincides with Text book on anatomy by Hollinshead. Henry. W (1958), Romanes. G .J (1972), Chummy. S. Sinnatamby (1999), and Susan Stand ring (2008) who had reported the IPDA either arises from the SMA or from the first jejunal branch.

Piersol. A. George (1930) reported that IPDA arises from SMA, occasionally from upper most intestinal branch. ${ }^{9}$ In the present study, the IPDA arose from the second jejunal branch in $1(2 \%)$ specimen.

Witte et al. (2001) and Deepthinath. R et al. (2010) had reported the absence of IPDA. In the present study the IPDA was absent in $3(6 \%)$ specimens. ${ }^{10}$

Unusual origin of IPDA was found in this study, in that the IPDA arose from MCA in $2(4 \%)$ specimens, which was not reported in any other literature mentioned above.

\section{Anomalous Origin of the IPDA (Dorsal Pancreatic Artery) \\ Rio brano (1912) found dorsal pancreatic artery (DPA) originating from coeliac trunk in one case. Bergman et al. (1988) had reported some variations of dorsal pancreatic artery. In this report the dorsal pancreatic artery originated}

from the splenic artery in $37 \%$ of cases, the coeliac artery in $33 \%$, the SMA in $8 \%$ of cases. ${ }^{11}$

\begin{tabular}{|ccc|}
\hline Sources of Origin of DPA & Bergman et al. & Present Study \\
Splenic artery & $37 \%$ & - \\
Coeliac artery & $33 \%$ & $100 \%$ \\
SMA & $21 \%$ & - \\
\hline Table 2. Comparison of the Sources of Origin of DPA \\
\hline
\end{tabular}

In current study the IPDA was absent in 3 (6\%) specimens, and the dorsal pancreatic artery arose from the coeliac trunk in the all three (100\%) specimens. which was higher than the findings of Bergman et al. (33\%).

In the present study, no dorsal pancreatic artery arose from the splenic or SMA as mentioned by the Bergman et al.

\section{Middle Colic Artery}

In the present study, the MCA was observed to originate from the right side of SMA in 48 (96\%) specimens, which correlates with Text book on anatomy by Hollinshead. Henry.W (1958), Chummy. S. Sinnatamby (1999), Moore, Arthur (1999), they quoted that the MCA arose from the right side of the SMA. ${ }^{12,13}$

Vandamme \& schuren (1976) had reported the absence of MCA in one $(0.64 \%)$ specimen. ${ }^{14}$ In the study of Radha krishnayya (1990), MCA was found to be absent in 2 (4\%) specimens. Nirmaladevi had reported the absence of MCA in 2 (4\%) specimens. ${ }^{15}$ In the present study, the MCA was absent in $2(4 \%)$ specimens, which correlates with the findings of Radhakrishnayya and Nirmaladevi.

In 1 specimen, it was observed that the MCA was divided into 4 branches, which was not reported in any other literature mentioned above.

\begin{tabular}{|cccc|}
\hline Authors & No. of Specimen Studied & No. of MCA Absent & $\%$ \\
\hline Vandamme & 156 & 1 & $0.64 \%$ \\
Steward \& Rankin & 40 & 2 & $5 \%$ \\
Radhakrishnayya & 25 & 2 & $4 \%$ \\
Nirmala Devi & 50 & 2 & $4 \%$ \\
Present Study & 50 & 2 & $4 \%$ \\
\hline Table 3. Comparison Table Showing Absence of Middle Colic Artery \\
\hline
\end{tabular}

\section{Right Colic Artery}

Out of 50 specimens, the RCA was observed in 47 (94\%) specimens and absent in 3 (6\%) specimens.

Waldeyer (1899) reported the origin of the RCA from SMA in $50 \%$ of cases. Sonneland et al. (1958) reported the presence of RCA in $78 \%$ of cases. Nirmaladevi (2008) reported the presence of RCA in $86 \%$ of cases. ${ }^{15,16}$

In the present study the RCA was observed in 47 (94\%) specimens, all of which arose from the SMA. It was higher than the findings of Waldeyer, Steward and Rankin, Sonneland et al.

Steward and Rankin observed no RCA in $18 \%$ of cases. ${ }^{17}$ Sonneland et al. reported the absence of RCA in $12.6 \%$ of cases. ${ }^{16}$ Michel's (1963) reported the absence of RCA in $2 \%$ of cases. ${ }^{18,19,20}$

In the present study the RCA was absent in 3 (6\%) specimens which was lower than the findings of Steward and Rankin Sonneland and it was higher than the findings of Michel's. 


\section{Ileocolic Artery}

In the present study, the ICA was observed in the all 50 specimens. Textbook on anatomy by Basmajian. V. John, Hollinshead. Henry. W, had reported that the ICA arose from the concave right side of the SMA. ${ }^{21}$ In the present study, in all specimens, the ICA arose from the concave right surface of the SMA. It divided into superior and inferior divisions after passing $5-8 \mathrm{~cm}$ transversely from the main stem of superior mesenteric artery, which confirms the findings of the above mentioned author.

Vandamme \& schuren (1976), Rob and Smith's (1993), Garcia et al. (1996) Corman. L. Marvin had reported that ICA is the most constant collateral of the SMA. ${ }^{15,22}$ In this present the ICA was present in all the 50 specimen which correlates with the above mentioned authors finding.

Hollinshead. Henry. W, Basmajian. V. John, and Bruce. G. Wolff had stated the ICA divided into superior and inferior branches. ${ }^{6,21,23}$ From the inferior division arose the anterior caecal, posterior caecal, ileal branch and the appendicular artery. In the present study, all the 50 ICA divided into superior and inferior branches. From the inferior division anterior caecal, posterior caecal, ileal branch, appendicular artery arose. This correlates with the above author's findings. ${ }^{24,25}$

In one specimen the ileocolic artery was found to divide within $1.5 \mathrm{~cm}$ of its origin from its main trunk, which was not reported by any other literature mentioned above.

\section{Jejunal and Ileal Branches}

Text Book on anatomy by Romanes.G.J (1972), Piersol. A George (1930), had reported that the jejunal and ileal branches arose from left side of SMA, usually 10 to 16 in number and were distributed to the jejunum and ileum. ${ }^{26,27,9}$

Text Book on anatomy by Moore, Arthur (1999), and Susan Stand ring (2008) said that the jejunal and ileal branches arose from the left side of SMA, usually 12 to 18 in number and were distributed to jejunum and ileum. ${ }^{28,1}$

Igiri.A.0 et al. (2010) had reported that in $60 \%$, the jejunal arteries were 2 in number and ileal arteries were 7 in number. All those arose from left side of SMA. In $26.7 \%$ the jejunal arteries were 3 in number and there were no ileal branch. In $13.3 \%$, the jejunal artery was one in number. ${ }^{29}$

In the present study, the number of jejunal and ileal branches ranged from 6 to 12 which was lower than the findings of anatomical Text books, it was higher than the findings of the Igiri. A. 0 et al.4,5,6,26,7

\section{CONCLUSIONS}

In the present study

- The Inferior pancreatic duodenal artery arose from the superior mesenteric artery in $68 \%$, from $1^{\text {st }}$ jejunal in 10 $\%$, from the middle colic artery in $4 \%$ and from the $2^{\text {nd }}$ jejunal in $2 \%$.

- The inferior pancreaticoduodenal artery was absent in 6 $\%$.

- Anomalous inferior pancreaticoduodenal artery (dorsal pancreatic artery) was present in $6 \%$ and in all those specimens it arose from coeliac trunk (100\%).
- The middle colic artery originated from the concave right side of the superior mesenteric artery in $96 \%$. It was absent in $4 \%$.

- The middle colic artery divided into right and left branches in $98 \%$.

- The middle colic artery divided into four branches and anastomose with each other in $2 \%$.

- The right colic artery arose from the concave right surface of the superior mesenteric artery in $94 \%$, and it was absent in $6 \%$.

- The ileo colic artery was a branch in all (100\%) the superior mesenteric artery.

- The ileo colic artery divided into superior and inferior branches after passing $5-8 \mathrm{~cm}$ transversely from the main stem of superior mesenteric artery in $98 \%$.

- In $2 \%$ the ileo colic artery divided into superior and inferior branches within $1.5 \mathrm{~cm}$ of its origin from the main stem of the superior mesenteric artery.

- The total number of jejunal and ileal branches range from $6-12$.

The integrity of the vascular structures in the vicinity of the superior mesenteric artery is of primary importance in the successful transplantation of liver and pancreas.

Data sharing statement provided by the authors is available with the full text of this article at jemds.com.

Financial or other competing interests: None.

Disclosure forms provided by the authors are available with the full text of this article at jemds.com.

\section{REFERENCES}

[1] Stranding S. Gray's Anatomy. 14th edn. 2008.

[2] Adachi B. Das Arteriensystem der Japener. Kyoto: Verlag der Kaiserlich-Japanischen Universität zu Kyoto 1928.

[3] Kalavathy. Study of celiac axis in 75 cadavers Institute of Anatomy MMC 1980.

[4] Chummy S. Sinnatamby. Last's anatomy. $10^{\text {th }}$ edn. 1999:238-9.

[5] Hollinshed HW. Anatomy for surgeons. Vol. 2. 1961.

[6] Hollinshead HW. Text Book of Anatomy. $5^{\text {th }}$ edn. 1966:648-50.

[7] Romanes GJ. Cunninghams manual of practical anatomy. Vol. 2. $15^{\text {th }}$ edn. 1893.

[8] Hamilton WJ. Text book of human Anatomy. 2nd edn. 1977:262-3.

[9] Piersol GA. Human anatomy: including structure and development and practical considerations. $8^{\text {th }}$ edn. 1930:801-2.

[10] Witte B, Frober R, Linss W. Unusual blood supply to the pancreas by a dorsal pancreatic artery. Surg Radiol Anat 2001;23(3):197-200.

[11] Bergman RA, Thompson SA, Afifi AK, et al. Compendium of human anatomic variation: text, atlas and world literature. Baltimore, Munich: Urban \& Schwarzenberg 1988.

[12] Moynihan B. Abdominal operations. Philadelphia: Saunders 1913. 
[13] Quain R. The anatomy of the arteries of the human body with its applications to pathology and operative surgery. Vol. 2. London: Taylor and Walton 1844.

[14] Vandamme JPJ, Van Der Schuren G. Re-evaluation of the colic irrigation from the SMA. Act Anatomica 1956;95:578-88.

[15] Nirmaladevi M. Variations in the origin and colic branches of the superior mesenteric artery. The Tamil Nadu Dr. M.G.R. Medical University 2008.

[16] John S, Anson BJ, Reaton LE. Gynaecology and obstetrics. 1958;106(4):384-98.

[17] Steward JA, Rankin FW. Blood supply of the large intestine: its surgical considerations. Arch Surg 1933;26:843.

[18] Michels NA. Blood supply of upper abdomen organs. philodelphia: JB Lippincott Company 1955.

[19] Michels NA. Variations in the blood supply of the supramesocolic organs. J Int Coll Surg 1949;12(5):625-7.

[20] Keighley K, Williams N. Surgery of the anus, rectum and colon. $3^{\text {rd }}$ edn. Elsevier 2008:8-10.

[21] Grant JCB, Basmajian JV, Slonecker CE. Grants Method of Anatomy. $11^{\text {th }}$ edn. USA: Lippincott Williams and Wilkins 1989:171-3.
[22] Fielding LP. Rob and Smith's surgery of colon, rectum and anus. $5^{\text {th }}$ edn. 1993:9-10.

[23] Marvin L. Corman colon and rectal surgery. $5^{\text {th }}$ edn. 2004:19-20.

[24] Higashi N, Hirai K. On the hepatic artery arising from the superior mesenteric artery. Kaibogaku Zasshi 1995;70(4):338-46.

[25] Koizumi M, Horiguchi M. Accessory arteries supplying the human transverse colon. Acta Anat (Basel) 1990;137(3):246-51.

[26] Romanes GJ. Cunninghams text book of Anatomy. 11 th edn. London: Oxford University Press 1972.

[27] Petrella S, De Souza Rodriguez CF, Sgrott EA, et al. Anatomy and variations of the celiac trunk. International Journal of Morphology 2007;25(2):249-57.

[28] Moore L, Dalley AF. Clinically oriented anatomy. $4^{\text {th }}$ edn. 1999:244-52.

[29] Igiri O, Ekong MB, Egemba GO, et al. The pattern of arrangements and distribution of the superior mesenteric artery in a Nigerian population. Int J Morphol 2010;28(1):33-6. 